\title{
Utilização de resíduos lignocelulósicos na produção de celulases por Aspergillus niger em fermentação em estado sólido
}

Use of lignocellulosic residues in the production of cellulases by Aspergillus niger in solid state fermentation

\author{
P. A. W. Cavalcante ${ }^{1 *}$; D. F. Coêlho${ }^{1}$; C. F. Silva1' A. K. S. Abud ${ }^{2}$; R. R. de \\ Souza ${ }^{1}$
}

${ }^{1}$ Departamento de Engenharia Química/Laboratório de Biotecnologia Ambiental, Universidade Federal de Sergipe, 49100-000, São Cristóvão-SE, Brasil

${ }_{2}^{2}$ Departamento de Tecnologia de Alimentos/Universidade Federal de Sergipe, 49100-000, São Cristóvão-SE, Brasil

*paulaacioly@outlook.com

(Recebido em 22 de julho de2017; aceito em 07 de maio de 2018)

\begin{abstract}
A biomassa vegetal é um recurso orgânico renovável e abundante, rica em componentes como celulose, hemicelulose e lignina. Este material é aproveitado como substrato na produção de celulases, pois a celulose presente pode ser convertida em carboidratos e, por meio de processos fermentativos, em combustíveis e outros produtos de alto valor agregado. O presente trabalho teve como objetivo estudar o potencial dos resíduos de folhas, bagaço de cana-de-açúcar e sabugo de milho na produção de celulases a partir do fungo A. niger por cultivo em estado sólido. O processo fermentativo foi realizado em Erlenmeyers de $250 \mathrm{~mL}$, contendo 7,5 g de substrato e volume de solução nutriente suficiente para atingir 55\% de umidade. Os frascos foram incubados a $30{ }^{\circ} \mathrm{C}$ durante $120 \mathrm{~h}$. O perfil cinético foi delineado a partir das atividades enzimáticas de celulase total (FPase) e endoglucanase (CMCase), dos açúcares redutores totais (ART) e do crescimento microbiano. Para as folhas, as maiores atividades foram obtidas em 48 e $72 \mathrm{~h}$, com $0,78 \pm 0,00$ $\mathrm{U} / \mathrm{g}$ para FPase e 1,53 $\pm 0,01 \mathrm{U} / \mathrm{g}$ para CMCase, respectivamente. No caso do bagaço de cana, a FPase atingiu maior atividade em $120 \mathrm{~h}(1,09 \pm 0,01 \mathrm{U} / \mathrm{g})$, enquanto a CMCase foi maior em $72 \mathrm{~h}(2,40 \pm 0,02$ $\mathrm{U} / \mathrm{g})$. O sabugo de milho exibiu maior atividade em $120 \mathrm{~h}$ para a FPase $(1,06 \pm 0,01 \mathrm{U} / \mathrm{g})$ e em $96 \mathrm{~h}$ para CMCase $(3,37 \pm 0,02 \mathrm{U} / \mathrm{g})$. Os resultados indicaram a capacidade do fungo de produzir celulases nos resíduos e em curtos tempos de incubação.

Palavras-chave: celulase, Aspergillus niger, fermentação em estado sólido
\end{abstract}

Vegetal biomass is a renewable and abundant organic resource, rich in cellulose, hemicellulose and lignin in its composition. This material is used as a substrate in the production of cellulases, because the cellulose present can be converted to carbohydrates and, through fermentation processes, into fuels and other products with high added value. The present work aimed to study the potential of leaves residues, sugarcane bagasse and corn cob to produce cellulases from A. niger fungus by solid state cultivation. The fermentation process was carried out in $250 \mathrm{~mL}$ Erlenmeyers containing $7.5 \mathrm{~g}$ of substrate and volume of nutrient solution sufficient to reach $55 \%$ moisture. Each flask was incubated at $30{ }^{\circ} \mathrm{C}$ for $120 \mathrm{~h}$. The kinetic profile was delineated for the enzymatic activities of total cellulase (FPase) and endoglucanase (CMCase), total reducing sugars (TRS) and microbial growth. For the leaves, the best results were obtained at 48 and $72 \mathrm{~h}$, with $0.78 \pm 0.00 \mathrm{U} / \mathrm{g}$ for FPase, and $1.53 \pm 0.01 \mathrm{U} / \mathrm{g}$ for CMCase, respectively. In the case of sugarcane bagasse, FPase reached the highest activity in $120 \mathrm{~h}(1.09 \pm 0.01 \mathrm{U} / \mathrm{g})$, while the CMCase was higher in 72 $\mathrm{h}$ with $(2.40 \pm 0.02 \mathrm{U} / \mathrm{g})$. Corn cob experiments showed higher activity at $120 \mathrm{~h}$ for FPase $(1.06 \pm 0.01 \mathrm{U} / \mathrm{g})$ and at $96 \mathrm{~h}$ for CMCase $(3.37 \pm 0.02 \mathrm{U} / \mathrm{g})$. The results indicated the fungus ability to produce cellulases in the residues and in short incubation times.

Keywords: cellulase, Aspergillus niger, solid state fermentation

\section{INTRODUÇÃO}

Recurso orgânico renovável e abundante, a biomassa lignocelulósica tem como componentes principais os polímeros: celulose, hemicelulose e lignina. Os resíduos agroindustriais, tais como palha de milho, bagaço de cana-de-açúcar e palha de trigo, são alguns exemplos deste tipo de 
material, tendo como alternativa para a sua conversão em vários produtos de valor agregado a hidrólise da lignocelulose em açúcares solúveis, quando esses açúcares são metabolizados por vias naturais ou modificados de acordo com a sua finalidade. No entanto, a biomassa lignocelulósica é resistente à biodegradação pelos microrganismos devido às suas propriedades estruturais e químicas, sendo fundamental o uso de enzimas [1,2].

Em comparação aos catalisadores químicos, as enzimas são mais eficazes, pois oferecem processos muito mais competitivos. Atualmente, o número de aplicações industriais das enzimas é elevado, principalmente devido aos avanços na tecnologia de engenharia de proteínas e das necessidades econômicas e ambientais. A enzima celulase, formada por endoglucanase, exoglucanase e $\beta$-glicosidase, apresenta uma vasta utilização nas indústrias de biocombustíveis, de celulose e papel, de detergente e têxtil. Esta enzima é capaz de despolimerizar, eficazmente, as cadeias de celulose no substrato lignocelulósico para produzir menores unidades de açúcar, que consistem em celobiose e glicose $[3,4]$.

A celulase pode ser produzida por microrganismos, como fungos e bactérias, sendo dada ênfase à produção pelos fungos filamentosos do gênero Aspergillus. Embora também seja produzida por fermentação submersa, a maioria dos estudos relata sua produção pela fermentação em estado sólido, já que apresenta um processamento mais simples e com baixo risco de contaminação [5].

A fermentação em estado sólido (FES) envolve a matriz sólida (substrato), que pode ser a fonte de nutrientes, ou apenas um suporte impregnado pelos nutrientes necessários para $\mathrm{o}$ desenvolvimento dos microrganismos. Trata-se de um processo realizado na ausência ou quase ausência de água livre. Para obter fermentações com altos rendimentos, deve-se levar em consideração a relação entre a fisiologia dos microrganismos e os fatores físico-químicos do processo. Estes fatores incluem a temperatura, $\mathrm{pH}$, aeração, atividade de água e umidade, natureza do substrato sólido, entre outros [6].

Dentre as fontes de matérias-primas lignocelulósicas com alta disponibilidade e que podem ser utilizadas como substrato, estão o sabugo de milho e o bagaço de cana-de-açúcar. O sabugo de milho é o principal resíduo gerado na colheita e processamento da cultura do milho, cujo alto teor de carboidratos o torna uma matéria-prima promissora para a produção de etanol de segunda geração. No entanto, a complexidade da estrutura dos carboidratos presentes faz com que seja imprescindível a realização de etapas de pré-tratamento, de modo a auxiliar sua hidrólise e, por conseguinte, sua digestibilidade [7].

O bagaço de cana-de-açúcar é o resíduo gerado do processamento da cana-de-açúcar em usinas ou destilarias para a obtenção do caldo de cana, matéria-prima na produção de etanol e açúcar. Embora seja majoritariamente utilizado na geração de vapor para o suprimento de energia de seu parque industrial, o bagaço pode ser utilizado na produção de ração animal, fabricação de papel e etanol de segunda geração, através de sua hidrólise. Estima-se que $280 \mathrm{~kg}$ de bagaço sejam gerados para cada tonelada de cana cana-de-açúcar moída [8].

A finalidade deste trabalho foi avaliar o potencial de resíduos lignocelulósicos, como resíduos de folhas, bagaço de cana-de-açúcar e sabugo de milho, na produção de celulases a partir do fungo filamentoso Aspergillus niger por fermentação em estado sólido.

\section{MATERIAL E MÉTODOS}

Os experimentos foram realizados no Laboratório de Biotecnologia Ambiental (LABAM) da Universidade Federal de Sergipe (UFS). Os ensaios de fermentação e extração do caldo enzimático foram baseados na metodologia descrita por Mrudula e Murugammal (2011) [9], com algumas modificações em termos de tempo de fermentação, quantidade de substrato, umidade inicial, entre outros.

A escolha dos valores do $\mathrm{pH}$ e da umidade inicial do meio de fermentação teve embasamento em dados pesquisados na literatura. $\mathrm{O}$ valor do $\mathrm{pH}$ inicial foi escolhido em função do crescimento dos microrganismos, ou seja, de acordo com a faixa de valores onde o crescimento do Aspergillus niger era mais favorável, já que o gênero Aspergillus pode ser cultivado em um intervalo de $\mathrm{pH}$ de 2 a 11 [10]. Além disso, em seus estudos, Oberoi et al. (2014) [11] constataram que a produção 
de celulases, a partir dos fungos Aspergillus niger, não foi muito afetada quando o $\mathrm{pH}$ inicial variou na faixa de 4 a 7. Já a umidade inicial da amostra foi definida com base no teor de água suportado pela fermentação em estado sólido, de modo que não excedesse a capacidade máxima de retenção de água do substrato, visto que, segundo Chen (2013) [12], a quantidade de água no substrato deve ser mantida na faixa de 12 a $80 \%$, principalmente em torno de $60 \%$.

$\mathrm{O}$ microrganismo utilizado foi o fungo filamentoso Aspergillus niger, isolado do solo pelo Grupo de Engenharia de Sistemas Biológicos (BIOSE) da Universidade Federal do Rio de Janeiro e cedido pelo Departamento de Tecnologia de Alimentos (DTA) da Universidade Federal de Sergipe (UFS).

O inóculo foi preparado adicionando $50 \mathrm{~mL}$ de solução estéril de Tween 80 a $0,01 \%$ (v/v) aos frascos Erlenmeyers contendo os microrganismos no meio PDA (Potato Dextrose Agar), para desprender os esporos a partir da raspagem e agitação. Em seguida, a suspensão de esporos foi transferida para outro frasco esterilizado e armazenada a $4{ }^{\circ} \mathrm{C}$.

Os substratos lignocelulósicos (resíduos de folhas, bagaço de cana-de-açúcar e sabugo de milho) foram moídos e classificados usando peneira Tyler 20, e as amostras foram utilizadas in natura (sem pré-tratamento). Os resíduos de folhas foram coletados na região adjacente ao LABAM, sendo uma mistura de diferentes tipos de plantas, predominantemente folhas de Moringa oleifera e Azadirachta indica, conhecida popularmente como Nim.

Algumas pesquisas relatam as composições típicas dos três componentes: celulose, hemicelulose e lignina de diferentes materiais lignocelulósicos. Em geral, as folhas possuem de 15 a $20 \%$ de celulose, 80 a $85 \%$ de hemicelulose e não apresentam quantidades mensuráveis de lignina, como mostra o estudo de Howard et al. (2003) [13]. No entanto, de acordo com as peculiaridades de cada planta e com as condições de análises, estes valores podem variar, como no caso das folhas de Moringa oleifera que são constituídas de 6,6\% de celulose, 3,2\% de hemicelulose e 1,3\% de lignina [14], e das folhas de Azadirachta indica que apresentam $20 \%$ de celulose, $20,5 \%$ de hemicelulose e $14 \%$ de lignina em sua parede vegetal [15]. O bagaço de canade-açúcar é composto por $45,4 \%$ de celulose, $28,7 \%$ de hemicelulose e $23,4 \%$ de lignina [16]. No sabugo de milho, a porcentagem de celulose em sua estrutura é de $45 \%$, a hemicelulose de $35 \%$ e a lignina de $15 \%$ [13].

As fermentações em estado sólido foram realizadas em frascos Erlenmeyers de $250 \mathrm{~mL}$, contendo 7,5 g de substrato e o volume da solução nutriente suficiente para atingir 55\% de umidade, com pH inicial de 5,5. A solução nutriente era composta por: $\left(\mathrm{NH}_{4}\right)_{2} \mathrm{SO}_{4}, 10 \mathrm{~g} / \mathrm{L}$; $\mathrm{KH}_{2} \mathrm{PO}_{4}, 3 \mathrm{~g} / \mathrm{L} ; \mathrm{MgSO}_{4} .7 \mathrm{H}_{2} \mathrm{O}, 0,5 \mathrm{~g} / \mathrm{L} ; \mathrm{CaCl}_{2}, 0,5 \mathrm{~g} / \mathrm{L} ; \mathrm{FeSO}_{4} .7 \mathrm{H}_{2} \mathrm{O}, 0,005 \mathrm{~g} / \mathrm{L} ; \mathrm{MnSO}_{4} . \mathrm{H}_{2} \mathrm{O}$, $0,0016 \mathrm{~g} / \mathrm{L} ; \mathrm{ZnSO}_{4} .7 \mathrm{H}_{2} \mathrm{O}, 0,0014 \mathrm{~g} / \mathrm{L}$. Os frascos foram esterilizados em autoclave a $121{ }^{\circ} \mathrm{C}$ e 1 atm durante 15 minutos. Após o resfriamento, o meio foi inoculado com o volume de suspensão necessário para obter a concentração final de $2 \times 10^{7}$ esporos por grama de substrato sólido e, posteriormente, incubado a $30{ }^{\circ} \mathrm{C}$ por um período de $120 \mathrm{~h}$. Os frascos foram periodicamente submetidos à agitação suave.

Ao final da fermentação, água destilada foi adicionada em cada frasco Erlenmeyer, na proporção de $1: 10(\mathrm{~m} / \mathrm{v})$, misturando homogeneamente em um agitador rotativo a $120 \mathrm{rpm}$ e 30 ${ }^{\circ} \mathrm{C}$ durante $1 \mathrm{~h}$. Logo após o extrato enzimático foi filtrado a vácuo. Os extratos obtidos foram centrifugados a $800 \mathrm{xG}$ durante $15 \mathrm{~min}$, e o sobrenadante foi utilizado como fonte de enzima extracelular para a determinação da concentração de substrato (ART) e da atividade enzimática.

As atividades da celulase total (FPase) e da endoglucanase (CMCase) foram realizadas segundo metodologia descrita por Ghose (1987) [17]. Uma unidade de atividade enzimática (FPase e CMCase) é definida como a quantidade de enzima necessária para produzir $1 \mu \mathrm{mol}$ de açúcares redutores, como a glicose, por minuto sob as condições de análise [18]. A quantificação dos açúcares formados pela reação das enzimas presentes com o respectivo substrato foi feita através da análise da cor formada pela reação dos açúcares com solução DNS, de acordo com o apresentado por Miller (1959) [19]. A concentração de açúcar correspondente a uma dada medida de absorbância foi calculada através de uma curva padrão de glicose, obtida conforme descrito por Adney e Baker (1996) [20]. O método DNS também foi empregado na determinação de açúcares redutores totais no extrato enzimático. 


\section{RESULTADOS E DISCUSSÃO}

\subsection{Cinética de produção enzimática nos resíduos de folhas}

De acordo com a Figura 1, a atividade da celulase total (FPase) apresentou seu máximo em 48 h, com $0,78 \pm 0,00 \mathrm{U} / \mathrm{g}$, período no qual houve um decaimento no teor dos açúcares redutores totais e um aumento na concentração de esporos, indicando que o microrganismo consumiu o substrato para a produção de enzimas. Logo em seguida, verificou-se uma queda na atividade enzimática, a qual exibiu uma variação mínima entre 72 e 96 h, enquanto os açúcares redutores permaneceram em declínio, atingindo seu valor mínimo em $72 \mathrm{~h}$, ao mesmo tempo em que o crescimento microbiano atingiu o seu máximo. Nessa etapa, o fungo esgotou a quantidade de açúcar disponível no substrato e, como estava em uma fase de crescimento exponencial, essa concentração de açúcar, especialmente a glicose, não foi o suficiente para acompanhar o seu desenvolvimento, tornando possível a obtenção de mais açúcares por meio das enzimas já produzidas [21]. Isto é, em $72 \mathrm{~h}$, tanto o açúcar disponível no meio quanto as enzimas celulases foram consumidos pelos microrganismos para a produção de açúcares, contribuindo para o seu crescimento e consequente diminuição da atividade enzimática. Em 96 h, houve uma redução na concentração de esporos como consequência da morte ou crescimento lento dos fungos, à medida que o ART aumentou e a FPase diminuiu, uma vez que os fungos não estavam com o metabolismo ativo para a produção de enzimas. Em 120 h, os microrganismos voltaram a crescer, consumindo o açúcar do substrato e, com isso, proporcionando um leve acréscimo na atividade da celulase total.

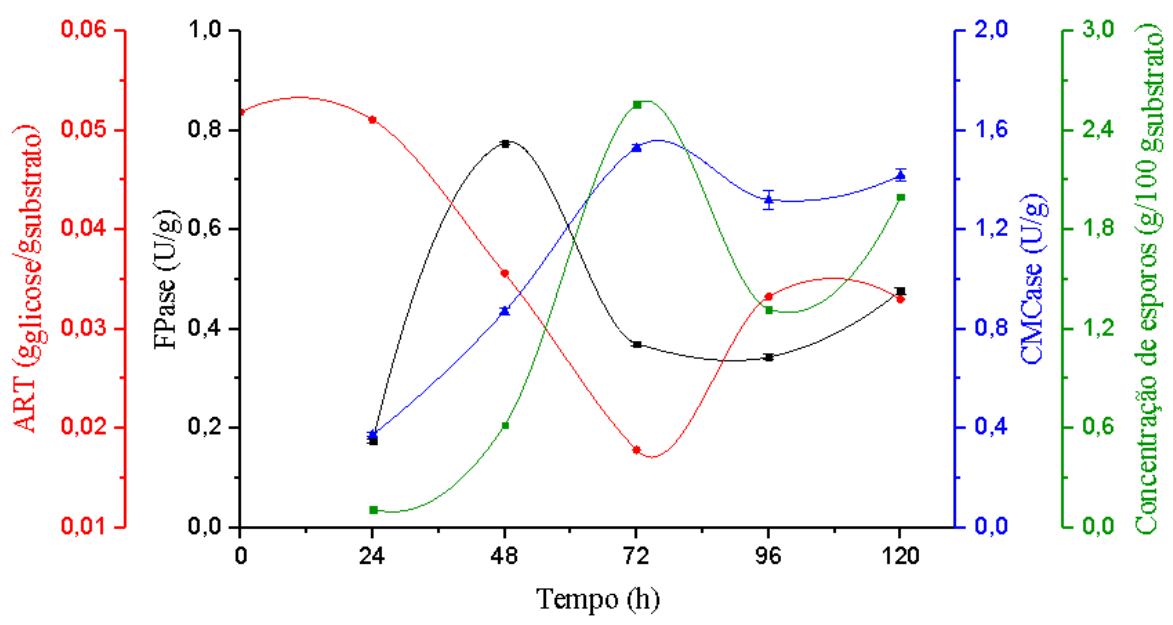

Figura 1: Cinética de crescimento do A. niger, ART, atividades da celulose total (FPase) e da endoglucanase (CMCase) em resíduos de folhas como fonte de carbono

O perfil da atividade enzimática da endoglucanase acompanhou o crescimento microbiano, alcançando seu máximo em 72 h (Figura 1). Conforme os microrganismos se desenvolveram, alimentando-se dos açúcares disponíveis no substrato, produziram a enzima em questão, a qual apresentou uma atividade de 1,53 $\pm 0,01 \mathrm{U} / \mathrm{g}$. Esta fase também foi caracterizada por uma menor concentração de açúcares redutores totais $\left(0,02 \mathrm{~g}_{\text {glicose }} / \mathrm{g}_{\text {substrato }}\right)$ e maior produção de esporos $(2,56$ $\mathrm{g}_{\text {esporos }} / 100 \mathrm{~g}_{\text {substrato }}$ ). Em 96 h, observou-se uma diminuição no crescimento fúngico e da atividade da endoglucanase, ao mesmo tempo em que não houve consumo de substrato, mas uma liberação de açúcares no meio, mostrando que os fungos, ainda ativos, liberaram enzimas para a hidrólise dos açúcares e para a sua reprodução, fato observado em 120 h, em que os esporos aumentaram sua concentração e, com isso, influenciaram na produção da CMCase, a qual apresentou atividade de $1,42 \pm 0,02 \mathrm{U} / \mathrm{g}$.

Como este estudo utilizou resíduos de folhas como fonte de carbono para a produção de celulases, foi inviável uma comparação mais minuciosa em torno dos demais substratos. Kumar 
et al. (2016) [22] avaliaram a influência de diferentes substratos na produção de celulases pelo fungo A. nidulans, destacando o resíduo da grama preta (Vigna mungo), parte da planta sem raiz e sementes, obtendo atividade máxima de celulase total de $1,50 \mathrm{U} / \mathrm{g}$ e endoglucanase de $61,7 \mathrm{U} / \mathrm{g}$. Nos estudos de Liang et al. (2012) [23], com Aspergillus sp. cultivado em grama de arroz (Spartina spp.), a atividade da celulase total foi de 1,14 U/g após a otimização das variáveis de fermentação. Essa diferença entre os valores da literatura e os encontrados neste trabalho é admissível, posto que as fermentações foram realizadas em condições específicas, com diferentes tipos de microrganismos e com grande variabilidade de substratos.

\subsection{Cinética de produção enzimática no bagaço de cana-de-açúcar}

Conforme a Figura 2, nas primeiras horas de fermentação utilizando o bagaço de cana-deaçúcar, o microrganismo apresentou um crescimento lento, seguido por uma fase de declínio, reduzindo-se consideravelmente até as $72 \mathrm{~h}$, visto que sua concentração de esporos caiu de 2,29 para $0,32 \mathrm{~g} / 100 \mathrm{~g}_{\text {substrato }}$ em um intervalo de tempo de $24 \mathrm{~h}$. Entretanto, percebe-se que, mesmo com a baixa concentração de esporos, a FPase continuou sendo produzida em taxas reduzidas, apenas com uma pequena queda em $96 \mathrm{~h}$, atingindo atividade máxima em $120 \mathrm{~h}(1,09 \pm 0,01 \mathrm{U} / \mathrm{g})$. A diminuição na atividade ocorreu simultaneamente ao aumento na produção de esporos, o que provavelmente foi causado pela utilização das enzimas como fonte de nutrientes para a reprodução dos fungos. Em 120 h, os perfis cinéticos apresentaram o comportamento esperado, ou seja, consumo do substrato pelo microrganismo e consequente produção enzimática.

Bansal et al. (2012) [24] utilizaram vários resíduos lignocelulósicos, dentre eles, o bagaço de cana-de-açúcar, para produzir celulases por A. niger em cultivo sólido. A atividade da celulase total foi $1,5 \pm 0,01 \mathrm{U} / \mathrm{g}$ no resíduo sem tratamento, assemelhando-se ao ponto de máxima atividade encontrado neste trabalho. De outra forma, no trabalho de Membrillo et al. (2008) [25], a produção da FPase por duas cepas de Pleurotus ostreatus, cultivadas no mesmo substrato, atingiu maior atividade $(0,013 \mathrm{U} / \mathrm{g})$ em $192 \mathrm{~h}$. Isto mostra que, mesmo compartilhando o substrato, a forma como o microrganismo age no consumo de nutrientes e as condições de fermentação (tamanho da partícula, temperatura, umidade, aeração, entre outros) são fatores cruciais para o andamento do processo.

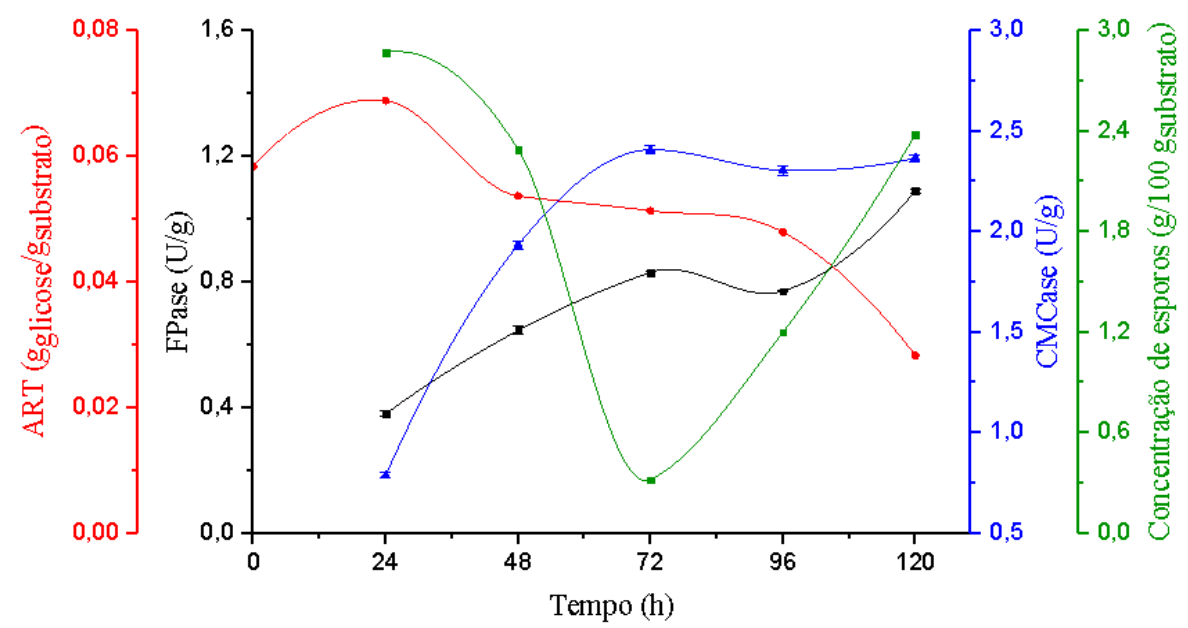

Figura 2: Cinética de crescimento do A. niger, ART, atividades da celulose total (FPase) e da endoglucanase (CMCase) em bagaço de cana-de-açúcar como fonte de carbono

Ainda analisando a Figura 2, nota-se que os microrganismos apresentaram crescimento nas primeiras horas de cultivo, contudo entraram em uma fase de declínio logo em seguida, atingindo seu mínimo em $72 \mathrm{~h}$, tempo no qual a endoglucanase atingiu sua atividade máxima $(2,40 \pm 0,02$ U/g). Entre 24 e 72 h, a atividade da endoglucanase aumentou, enquanto a produção de esporos diminuiu, mostrando que, apesar da pequena quantidade de microrganismos, os mesmos estavam 
metabolicamente ativos e propensos à degradação do substrato para a produção da enzima. Após seu máximo, a atividade teve uma leve redução em $96 \mathrm{~h}(2,30 \pm 0,02 \mathrm{U} / \mathrm{g})$, subindo novamente em $120 \mathrm{~h}$, o que coincidiu com o aumento na produção de esporos, sugerindo que a produção está relacionada com o bom desenvolvimento dos fungos.

Segundo Delabona et al. (2012) [26], há na literatura muitos trabalhos que indicam o gênero Aspergillus como bom produtor de endoglucanase. Em suas análises com o fungo Aspergillus fumigatus, cultivados em diferentes substratos (bagaço de cana-de-açúcar, farelo de trigo, farelo de soja e casca de laranja), os autores identificaram que a fonte de carbono exerce grande influência na atividade da CMCase, obtendo menores níveis de produção de endoglucanase no bagaço de cana (16,7 U/g) após $96 \mathrm{~h}$ de fermentação. Este valor é três vezes maior ao encontrado por Bansal et al. (2012) [24] com o fungo Aspergillus niger (5,00 $\pm 0,1 \mathrm{U} / \mathrm{g}$ ). Essa diferença entre os dois fungos pode ser notada nas pesquisas de Delabona et al. (2013) [27], nas quais obtiveram atividade de 8,50 U/g para o A. niger e 13,0 U/g para o A. fumigatus, em um estudo de umidade, indicando que a atividade da CMCase não é influenciada apenas pelo tipo de microrganismo, mas também por condições específicas impostas ao meio fermentado.

\subsection{Cinética de produção enzimática no sabugo de milho}

No início da incubação, no sabugo de milho, os fungos produziram maior quantidade de açúcares em comparação à produção de enzimas (Figura 3). Após as 24 h, os microrganismos começaram a consumir os açúcares disponíveis no sabugo e, assim, a atividade da celulase total apresentou acréscimo. As maiores atividades foram em $72(0,98 \pm 0,02 \mathrm{U} / \mathrm{g})$ e $120 \mathrm{~h}(1,06 \pm 0,01$ $\mathrm{U} / \mathrm{g}$ ), ambas com menores concentrações de esporos, sugerindo que os fungos resistiram a fatores capazes de inibir seu crescimento, ou até mesmo a morte, ingerindo os nutrientes do meio para a produção de FPase. Por volta das 96 h, os fungos estavam na sua fase de crescimento mais acentuada $\left(3,69 \mathrm{~g}_{\text {esporos }} / 100 \mathrm{~g}_{\text {substrato }}\right)$, consumindo o açúcar do substrato e parte liberado pelas enzimas produzidas, o que pode ser constatado pela ligeira queda da atividade. Os açúcares redutores totais diminuíram durante todo o tempo de incubação, sendo degradados tanto para o desenvolvimento dos fungos quanto para a produção da celulase total.

A atividade da celulase total encontrada por Deswal et al. (2011) [28] na produção de celulases por Fomitopsis sp. em sabugo de milho foi de $0,19 \pm 0,01 \mathrm{U} / \mathrm{g}$, valor inferior ao deste trabalho. Os resultados da FPase obtidos por Bansal et al. (2012) [24], utilizando o fungo Aspergillus niger em meio de cultivo contendo sabugo de milho, mostraram-se mais elevados do que os deste estudo, com níveis de 3,10 $\pm 0,06 \mathrm{U} / \mathrm{g}$, sugerindo que não somente a variabilidade do substrato, mas também a cepa do microrganismo influencia na obtenção das enzimas.

A endoglucanase apresentou maior atividade quando a concentração de esporos atingiu o seu máximo em 96 h, chegando a 3,37 $\pm 0,02 \mathrm{U} / \mathrm{g}$ (Figura 3), enquanto o teor de açúcares redutores totais foi reduzido à metade no período de $24 \mathrm{a} 96 \mathrm{~h}$. Além disso, a CMCase apresentou perda de atividade em $72 \mathrm{~h}$ e em $120 \mathrm{~h}$, sendo esta última fase acompanhada de uma grande redução no número de esporos, atingindo $0,86 \mathrm{~g}_{\text {esporos }} / 100 \mathrm{~g}_{\text {substrato }}$. Na segunda diminuição de atividade, os nutrientes que ainda restavam no substrato foram consumidos mais para o crescimento de novas células do que para a produção de enzimas, indicando que a atividade enzimática estava relacionada ao cultivo de esporos no meio, isto é, quanto mais microrganismos na plenitude de suas funções metabólicas, maior a atividade enzimática. Outra possível causa dessa redução seria o consumo da própria enzima pelos microrganismos, também com intuito de reprodução. 


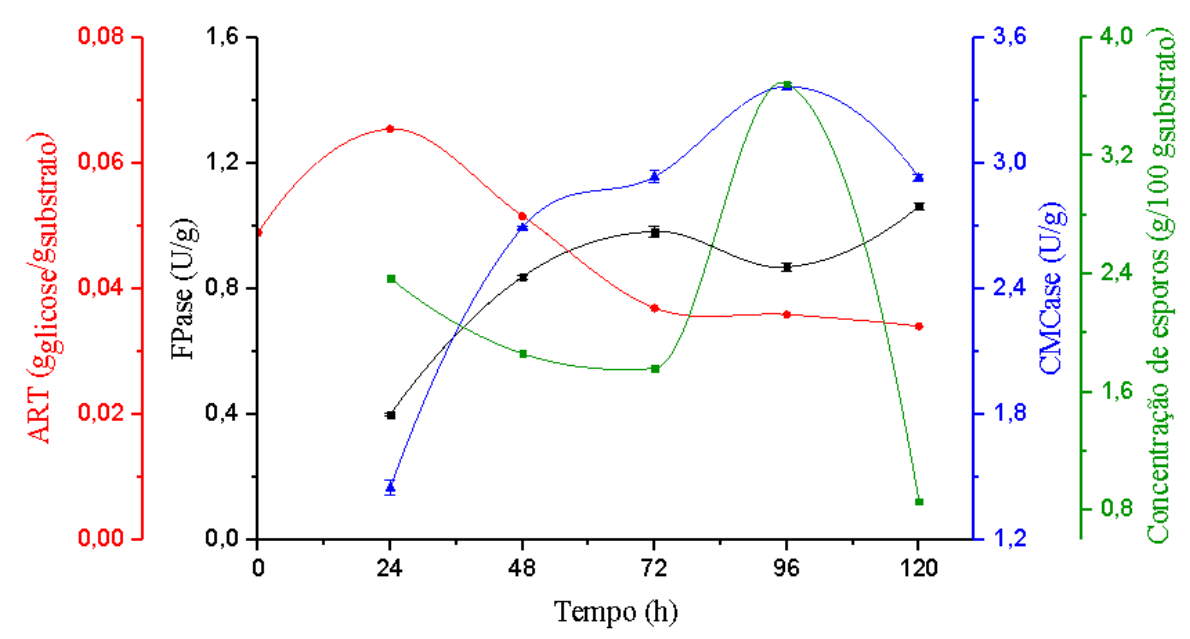

Figura 3: Cinética de crescimento do A. niger, ART, atividades da celulose total (FPase) e da endoglucanase (CMCase) em sabugo de milho como fonte de carbono

Deswal et al. (2011) [28] estudaram a influência de várias fontes de carbono na produção de celulases em meio sólido pelo fungo Fomitopsis sp., utilizando o sabugo de milho como um dos substratos, com atividade da endoglucanase de 2,22 $\pm 0,04 \mathrm{U} / \mathrm{g}$. Pandey et al. (2015) [29] analisaram oito espécies de Trichoderma para a produção de enzimas por fermentação em estado sólido em diferentes substratos, entre eles o sabugo de milho, o qual forneceu maior produção de celulases em todas as espécies. Liu et al. (2011) [30], usando palhas de arroz, trigo, milho e algodão na produção de celulases pelo fungo A. fumigatus, em $96 \mathrm{~h}$, observaram maiores atividades na palha de milho, com atividade de FPase e CMCase de 507,6 \pm 13,7 U/g e 100,8 \pm $4,3 \mathrm{U} / \mathrm{g}$, respectivamente. A capacidade de produção de celulases por uma espécie termoacidófila de Aspergillus terreus, em diferentes resíduos, foi analisada por Gao et al. (2008) [31], e os resultados do cultivo sólido com a palha de milho mostraram potencial promissor, com atividade da endoglucanase de $440 \mathrm{U} / \mathrm{g}$. Esses dados apontam a importância da escolha do microrganismo, da fonte de carbono e das condições de fermentação, uma vez que a atividade enzimática depende de tais fatores.

\section{CONCLUSÃO}

O fungo Aspergillus niger foi capaz de secretar celulases por fermentação em estado sólido utilizando os três resíduos lignocelulósicos como fonte de carbono. Entre os substratos analisados, o sabugo de milho apresentou a maior atividade enzimática, seguido pelo bagaço de cana-deaçúcar e pelos resíduos de folhas. Logo, verificou-se a potencialidade de todos esses substratos na produção da celulase total (FPase) e da endoglucanase (CMCase).

Embora os resultados apontem para uma boa produção de celulases com o sabugo de milho e o bagaço de cana-de-açúcar, os resíduos de folhas surgem como uma alternativa atraente para a produção dessas enzimas, pois, com posteriores estudos de otimização, podem-se obter valores de atividades mais elevados do que os encontados neste trabalho. Além disso, como esses resíduos não têm utilização comercial/econômica conhecida, por exemplo, não são usados como substrato na obtenção de biocombustíveis. Também como não há um meio de descarte apropriado, com possível reciclagem, a bioconversão dos resíduos de folhas e afins é uma maneira eficiente para minimizar os impactos ambientais causados pelo descarte incorreto e para utilizar uma fonte barata e rica de nutrientes para obter produtos com alto valor agregado.

\section{AGRADECIMENTOS}

Os autores gostariam de agradecer a CAPES e ao CNPq pelo suporte financeiro e concessão de bolsas. 


\section{REFERÊNCIAS BIBLIOGRÁFICAS}

1. Biswas R, Persad A, Bisaria VS. Production of cellulolytic enzymes. In: Bisaria VS, Kondo A, editors. Bioprocessing of Renewable Resources to Commodity Bioproducts. 1st ed. Hoboken, New Jersey: John Wiley \& Sons; 2014. p. 105-32, doi: 10.1002/9781118845394.ch5.

2. Zheng Y, Zhao J, Xu F, Li Y. Pretreatment of lignocellulosic biomass for enhanced biogas production. Prog Energy Combust Sci. Elsevier Ltd; 2014;42(1):35-53, doi:10.1016/j.pecs.2014.01.001.

3. Choi J-M, Han S-S, Kim H-S. Industrial applications of enzyme biocatalysis: current status and future aspects. Biotechnol Adv. Elsevier Inc.; 2015;33(7):1-12, doi:10.1016/j.biotechadv.2015.02.014.

4. Yoon LW, Ang TN, Ngoh GC, Chua ASM. Fungal solid-state fermentation and various methods of enhancement in cellulase production. Biomass Bioenergy. Elsevier Ltd; 2014;67:319-38, doi:10.1016/j.biombioe.2014.05.013.

5. Castro RJS de, Sato HH. Enzyme production by solid state fermentation: general aspects and an analysis of the physicochemical characteristics of substrates for agro-industrial wastes valorization. Waste Biomass Valorization. 2015;6(6):1085-93, doi:10.1007/s12649-015-9396-х.

6. Singhania RR, Patel AK, Soccol CR, Pandey A. Recent advances in solid-state fermentation. Biochem Eng J. 2009;44(1):13-8, doi:10.1016/j.bej.2008.10.019.

7. Pereira TV, Seye O. Caracterização fisica termica de biomassa local. CANA. 2014;45(43):5-71.

8. Oliveira JG. Perspectivas para a cogeração com bagaço de cana-de-açúcar. Dissertação de Mestrado, USP, São Carlos, Brasil. 2007.

9. Mrudula S, Murugammal R. Production of cellulase by Aspergillus niger under submerged and solid state fermentation using coir waste as a substrate. Brazilian J Microbiol. 2011;42(3):1119-27, doi:10.1590/S1517-83822011000300033.

10. Meyer V, Wu B, Ram AFJ. Aspergillus as a multi-purpose cell factory: Current status and perspectives. Biotechnol Lett. 2011;33(3):469-76, doi:10.1007/s10529-010-0473-8.

11. Oberoi HS, Rawat R, Chadha BS. Response surface optimization for enhanced production of cellulases with improved functional characteristics by newly isolated Aspergillus niger HN-2. Antonie van Leeuwenhoek, Int J Gen Mol Microbiol. 2014;105(1):119-34, doi:10.1007/s10482-013-0060-9.

12. Chen H. Introduction. In: Chen H, editor. Modern Solid State Fermentation: Theory and Practice. 1st ed. Springer; 2013. p. 1-21, doi:10.1007/978-94-007-6043-1.

13. Howard RL, Abotsi E, Jansen van Rensburg EL, Howard S. Lignocellulose biotechnology: Issues of bioconversion and enzyme production. African J Biotechnol. 2003;2(12):602-19, doi:10.5897/AJB2003.000-1115.

14. Kakengi AMV, Shem MN, Sarwatt S V., Fujihara T. Can Moringa oleifera be used as a protein supplement for ruminants? Asian-Australasian J Anim Sci. 2005;18(1):42-7, doi:doi.org/10.5713/ajas.2005.42.

15. Bakshi MPS, Wadhwa M. Tree leaves as complete feed for goat bucks. Small Rumin Res. 2007;69(13):74-8, doi:10.1016/j.smallrumres.2005.12.009.

16. Tye YY, Lee KT, Wan Abdullah WN, Leh CP. The world availability of non-wood lignocellulosic biomass for the production of cellulosic ethanol and potential pretreatments for the enhancement of enzymatic saccharification. Renew Sustain Energy Rev. 2016;60:155-72, doi:10.1016/j.rser.2016.01.072.

17. Ghose TK. Measurement of cellulase activities. Pure Appl Chem. 1987;59(2):257-68, doi:10.1351/pac198759020257.

18. Mansour AA, Da Costa A, Arnaud T, Lu-Chau TA, Fdz-Polanco M, Moreira MT, et al. Review of lignocellulolytic enzyme activity analyses and scale-down to microplate-based assays. Talanta. Elsevier; 2016;150:629-37, doi:10.1016/j.talanta.2015.12.073.

19. Miller GL. Use of dinitrosalicylic acid reagent for determination of reducing sugar. Anal Chem. 1959;31(3):426-8, doi:10.1021/ac60147a030.

20. Adney B, Baker J. Measurement of cellulase activities. Natl Renew Energy Lab. Golden, USA; 1996;111.

21. Oberoi HS, Babbar N, Dhaliwal SS, Kaur S, Vadlani P V., Bhargav VK, et al. Enhanced oil recovery by pre-treatment of mustard seeds using crude enzyme extract obtained from mixed-culture solid-state fermentation of Kinnow (Citrus reticulata) Waste and Wheat Bran. Food Bioprocess Technol. 2012;5(2):759-67, doi:10.1007/s11947-010-0380-y.

22. Kumar A, Dutt D, Gautam A. Production of crude enzyme from Aspergillus nidulans AKB-25 using black gram residue as the substrate and its industrial applications. J Genet Eng Biotechnol. Academy of Scientific Research \& Technology; 2016, doi:10.1016/j.jgeb.2016.06.004.

23. Liang X, Huang Y, Hua D, Zhang J, Xu H, Li Y, et al. Cellulase production by Aspergillus sp. on rice grass (Spartina spp.) under solid-state fermentation. African J Microbiol Res. 2012;6(39):6785-92, 
doi:10.5897/ajmr12.986.

24. Bansal N, Tewari R, Soni R, Soni SK. Production of cellulases from Aspergillus niger NS-2 in solid state fermentation on agricultural and kitchen waste residues. Waste Manag. Elsevier Ltd; 2012;32(7):1341-6, doi:10.1016/j.wasman.2012.03.006.

25. Membrillo I, Sánchez C, Meneses M, Favela E, Loera O. Effect of substrate particle size and additional nitrogen source on production of lignocellulolytic enzymes by Pleurotus ostreatus strains. Bioresour Technol. 2008;99(16):7842-7, doi:10.1016/j.biortech.2008.01.083.

26. Delabona P da S, Pirota RDPB, Codima CA, Tremacoldi CR, Rodrigues A, Farinas CS. Using Amazon forest fungi and agricultural residues as a strategy to produce cellulolytic enzymes. Biomass Bioenergy. 2012;37:243-50, doi:10.1016/j.biombioe.2011.12.006.

27. Delabona P da S, Pirota RDPB, Codima CA, Tremacoldi CR, Rodrigues A, Farinas CS. Effect of initial moisture content on two Amazon rainforest Aspergillus strains cultivated on agro-industrial residues: Biomass-degrading enzymes production and characterization. Ind Crops Prod. Elsevier B.V.; 2013;42(1):236-42, doi:10.1016/j.indcrop.2012.05.035.

28. Deswal D, Khasa YP, Kuhad RC. Optimization of cellulase production by a brown rot fungus Fomitopsis sp. RCK2010 under solid state fermentation. Bioresour Technol. Elsevier Ltd; 2011;102(10):6065-72, doi:10.1016/j.biortech.2011.03.032.

29. Pandey S, Srivastava M, Shahid M, Kumar V, Singh A, Trivedi S, et al. Trichoderma species cellulases produced by solid state fermentation. J Data Mining Genomics Proteomics. 2015;6(2):1-4, doi:10.4172/2153-0602.1000170.

30. Liu D, Zhang R, Yang X, Wu H, Xu D, Tang Z, et al. Thermostable cellulase production of Aspergillus fumigatus $\mathrm{Z} 5$ under solid-state fermentation and its application in degradation of agricultural wastes. Int Biodeterior Biodegrad. Elsevier Ltd; 2011;65(5):717-25, doi:10.1016/j.ibiod.2011.04.005.

31. Gao J, Weng H, Zhu D, Yuan M, Guan F, Xi Y. Production and characterization of cellulolytic enzymes from the thermoacidophilic fungal Aspergillus terreus M11 under solid-state cultivation of corn stover. Bioresour Technol. 2008;99(16):7623-9, doi:10.1016/j.biortech.2008.02.005. 